\title{
An Assessment of Operating Conditions for Supercritical Water Gasification and Safety Issues
}

\author{
Cataldo De Blasio ${ }^{1 *}$, Mauro Prestipino², Antonio Galvagno², Margareta Björklund-Sänkiaho' \\ ${ }^{1}$ Faculty of Science and Engineering, Åbo Akademi University \\ Rantakatu 2, 65100 Vaasa, Finland. \\ ${ }^{2}$ Department of Engineering - University of Messina, C.da Di Dio, 98166 Messina, Italy. \\ cdeblasi@abo.fi
}

\begin{abstract}
The research paper presented here describes experimental investigations of Black Liquor Supercritical Water Gasification in a continuous Plug Flow Reactor system. Operating conditions heavily affects the gasification yields within the process. Nevertheless, an important issue in SCWG is the possible deposition of tar, char and inorganic compounds with subsequent plugging of the reactor. Reactions of re-polymerization are taken into account in regards to the results obtained. Important considerations are given here concerning the design and operation of high pressure reactor systems aimed at SCWG of biomass. Operational issues are seldom taken into account in this kind of investigations.
\end{abstract}

Keywords: Supercritical Water Gasification, Operational Issues, Carbon Gasification Efficiency, Biomass Gasification

\section{Introduction}

Nowadays, the use of biofuels in energy conversion processes is of increasing interest, above all because biofuels are considered to be carbon neutral since they are produced from biomass.

The reasoning behind this is that plants and several other microorganisms can utilize $\mathrm{CO}_{2}$ contained in the atmosphere and therefore, when this biomass is utilized for power conversion processes, the carbon balance will be neutral. There are important limitations in this assumptions [1]. First of all, plants and organisms in general require relatively long time to produce biomass from photosynthetic processes [2]. In addition, it has to be considered that the extensive usage of energy cultivations is producing depletion of the soil with loss of nutrients and inorganic compounds, which are utilized during the photosynthetic process. Despite woody biomass is still the most diffused source of feedstock in thermochemical conversion processes, there is a great attention worldwide on residual biomasses [3-5].

Biomass gasification is intended to produce syngas to be utilized as fuel in power production and combined production systems [6]. For instance, internal combustion engines [7] and turbo gas [8] are the most common downstream application for power production. The commercially available technologies are numerous and provided by different companies; among others: General Electric, ConocoPhillips, Lurgi, Mitsubishi [9].

The first studies on the Supercritical Water Gasification, SCWG, of biomass date back to few years ago [10]. SCWG do present positive aspects [11]. For instance, it can be considered a form of gasification at low temperature since very good results could be obtained at temperatures around $600^{\circ} \mathrm{C}[12,13]$. Furthermore, there are also practical aspects which can be of advantage when bringing the reactor to the gasification conditions: by retaining the pressure above the supercritical point, it has been reported in literature [14] that there is even the possibility to save energy since the boiling process (very energy consuming) is avoided as can be seen from Figure 1. 


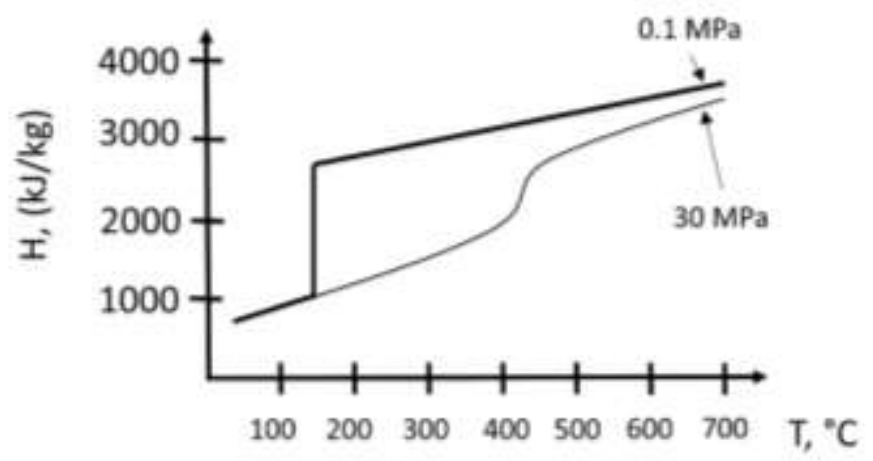

Fig. 1: Enthalpy Variation of Water against temperature at sub/supercritical conditions. Adapted from [14].

Operational issues of SCWG of biomass have been reported recently in literature [15] in regards to the problems caused by deposition of salts contained in feedstock like black liquor.

In the present study, authors report a more detailed description of the problematics encountered during continuous SCWG of biomass. In literature, it is seldom acknowledged that there are operational and safety issues which should be considered also from a reactor design point of view.

\section{Materials and methods}

In this study, experiments were conducted by utilizing a continuous mode of operation. Biomass is inserted first in a suitable feed cylinder by means of a valve system. Pressurized nitrogen is used first to pressurize the biomass sample and then to inject the sample into the reactor at the target operating conditions. For this purpose, a mass flow controller (ElFlow ${ }^{\circledR}$ F230-M from Bronkhorst High-Tech B.V.) was used and coupled with a check valve, pressure meter and ball valve (See Figure 3). All the valves and tubing used were from Swagelock. The reactors utilized for this investigation were made of Inconel 625 and Stainless Steel 316 respectively. Temperatures and pressures were taken at different places along the reactor and recorded by using the LabVIEW software. The data acquisition system is the NI DAQ mx from National Instruments. Gas and liquid products are collected in suitable gas sampling bags with septum and valve after the cooling section and a final back-pressure regulator. For elemental analysis, a CHNS analyser, Flash EA 1112 by Thermo Quest was used. While for gas analyses we used a gas chromatograph, Perkin Elmer Clarus 500 (with a TCD detector) by Arnel. The estimation of the Gross Calorific Value was performed by a Parr Instrument Company's 1341 Oxygen Bomb Calorimeter. A description is given in Figure 2.

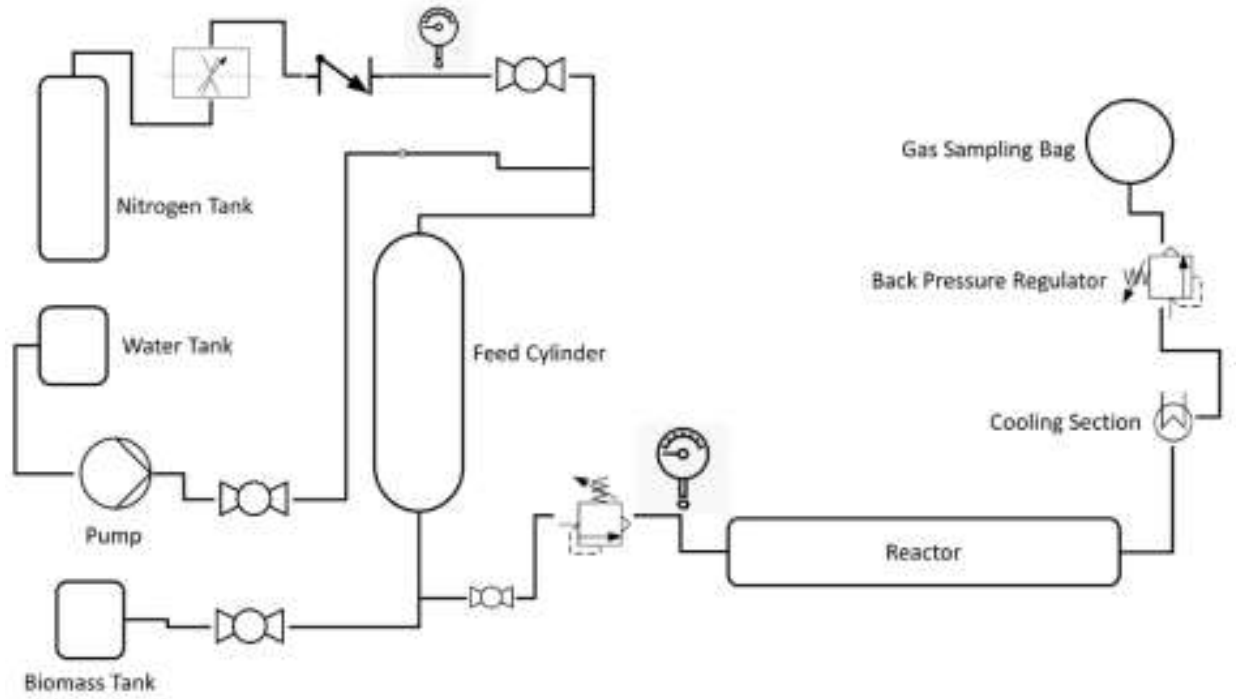

Fig. 2: SCWG Continuous flow reactor setup. 
The sample tested was weak black liquor from a Finnish pulp and paper company; Table 1 describes the sample composition in terms of elemental analysis. While Table 2 gives the Higher Heating Value and ash content.

Table 1: Black liquor composition.

\section{BLACK LIQUOR AS RECEIVED}

\begin{tabular}{|c|r|r|r|r|}
\hline $\begin{array}{c}\text { Sampl } \\
\text { e num. }\end{array}$ & $\begin{array}{r}\text { Sample } \\
\text { mass }[\mathbf{m g}]\end{array}$ & $\begin{array}{c}\text { C } \\
\text { \% wt }\end{array}$ & $\begin{array}{c}\mathbf{H} \\
\text { \%wt }\end{array}$ & $\begin{array}{r}\mathbf{S} \\
\text { \% wt }\end{array}$ \\
\hline $\mathbf{1}$ & 3,48 & 8,25 & 9,90 & 0,00 \\
\hline $\mathbf{2}$ & 2,62 & 8,93 & 9,36 & 0,11 \\
\hline $\mathbf{3}$ & 2,24 & 9,75 & 9,42 & 0,00 \\
\hline $\mathbf{4}$ & 1,77 & 8,28 & 8,97 & 0,00 \\
\hline $\mathbf{5}$ & 1,67 & 8,36 & 9,35 & 0,00 \\
\hline \multicolumn{2}{|c|}{ Average composition } & $\mathbf{8 , 7 1}$ & $\mathbf{9 , 4 0}$ & $\mathbf{0 , 0 2}$ \\
\hline
\end{tabular}

Table 2: Measurement of high heating value and ash content for dry black liquor.

Of particular interest is the configuration of the reactor closure system and the particular arrangements aimed at releasing the pressure in case of over-stressed conditions. This is shown in Figure 3 with the main parts shown in Table 3. In the same figure, the conical shaped connection (Cone) between the coupling and the reactor is shown together with the path followed by the fluid, in case it will release the pressure trough the safety hole. This arrangement is very useful and necessary when operating the SCWG of biomass.

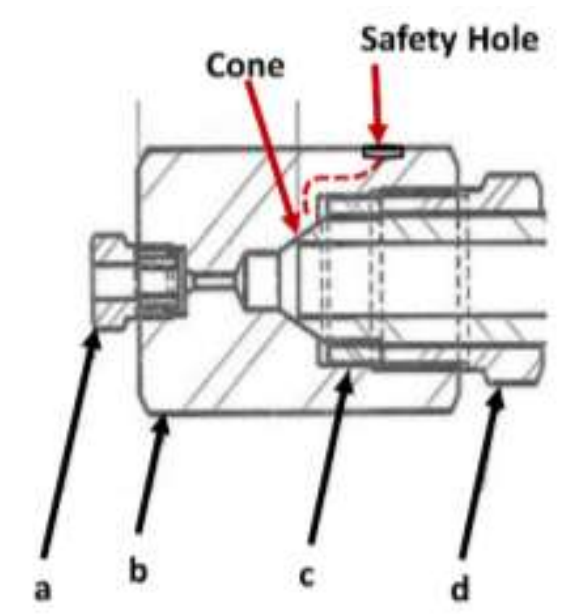

Table 3: Key parts within the reactor sealing.

\begin{tabular}{cc} 
Item & Description \\
\hline$a$ & Collar \\
\hline$b$ & Coupling \\
c & Collar \\
\hline$d$ & Gland \\
\hline
\end{tabular}

Fig. 3: Reactor closure system with safety arrangements.

\section{Results and Discussion}

Black liquor presents important positive aspects related to its composition. As a matter of fact, BL, contains already inorganic salts which act as homogeneous catalysts [16]. Even if the process of gasification is very much improved, phenomena like deposition and plugging can't be underestimated.

Importantly, when the concentration of biomass inside the reactor is relatively high, this could create an additional safety alarm especially when the reactor is definitely plugged since the biomass contained within the reactor will continue to increase the internal pressure even if the heating system is switched off. 
Figure 4 shows the sudden pressure drops encountered during the last period of the experimental session. The accumulation of char, tar and inorganics form a temporary closure to the inlet of the reactor. Because of an accumulation of pressure on top of the closure, the "wall" is totally or partially removed and this allows for a sudden inlet of feedstock. This is causing the quick pressure drops shown in Figure 4. The left side of the figure, (a), describes the pressure variation as function of time under temperature controlled conditions. In particular, it shows just a limited time range in which the sudden pressure drop occurs. This behavior is observed more often if the experiments are continued for longer time as demonstrated in Figure 4 (b). The measurement of the temperature is done at the reactor external wall. Because the metallic mass of the reactor is enormously large with respect to the internal mass of the feedstock, the temperature at the external wall does not suffer of any drastic variation.

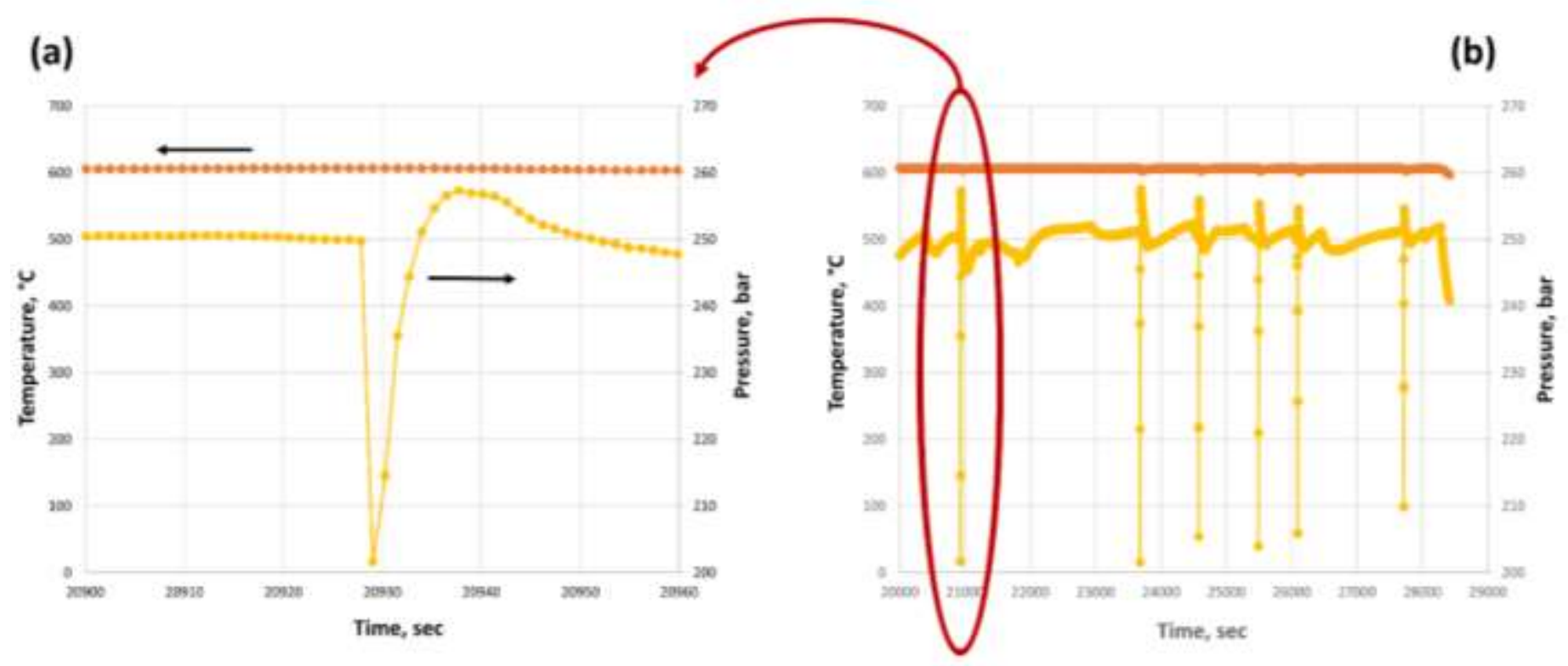

Fig. 4: Sudden pressure drop due to reactor plugging. (a) Single Drop; (b) multiple drops along the experimental time.

Figure 5 shows the Carbon Gasification Efficiency (CGE) as function of residence time at $600^{\circ} \mathrm{C}$ and $700^{\circ} \mathrm{C}$. The CGE represent the capacity of the process to convert the carbon of biomass into syngas. In addition, the CGE variation is shown for both catalytic and non-catalytic reactor. It is possible to observe that the effect of residence time is more relevant at $700^{\circ} \mathrm{C}$, where the difference between the two reactor is almost negligible. An interesting aspect to observe is that at $600^{\circ} \mathrm{C}$ the non-catalytic reactor shows a slight reduction of CGE with the residence time.

(a)

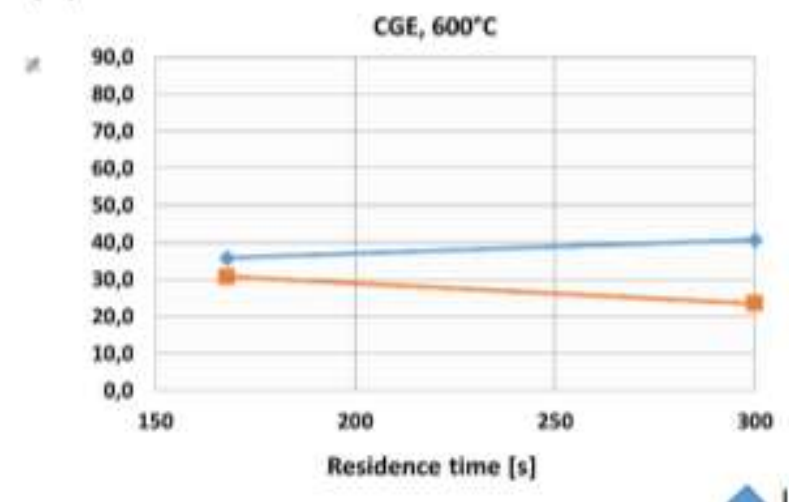

(b)

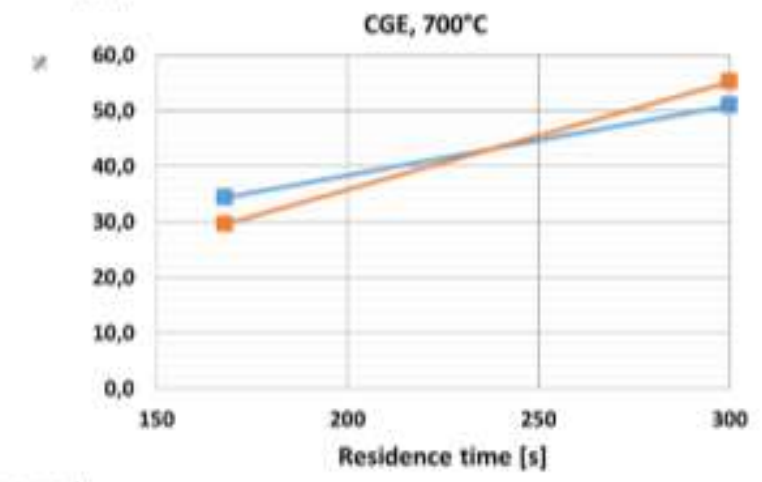

Inconel

Stainless Steel

Fig. 5: CGE at $600^{\circ} \mathrm{C}(\mathrm{b})$ and $700^{\circ} \mathrm{C}(\mathrm{c})$ as function of residence time. 
This is due to possible re-polymerization, which is a phenomena that could take place during gasification. One example can be the re-polymerization of phenolic compounds, this would reduce the gas yield [17].

At supercritical conditions, the dielectric constant of water is decreased importantly and this allows for the precipitation of salts and inorganics contained within the feedstock. In addition to this phenomenon, there is also tar and char deposition within the reactor and this is more accentuated at the inlet part of it, where the reactor's temperature is lower than the central section, as directly observed at the end of each test. This is confirmed by inspecting the reactor inlet and outlet and considering some additional phenomena taking place when plugging occurs. Because of these depositions, there is partial or total plugging and this will provoke sudden pressure drops/rise within the reactor. The pressure in the reactor can even have significantly higher values than the setup point of the backpressure regulator (Figure 5) and this is because the response time of the valve itself is not immediate.

The stress caused by sudden pressure drop/rise can have important consequences and lead to the breakage of the reactor during long operating conditions.

\section{Conclusions}

Supercritical Water Gasification can be addressed as an effective way to produce syngas from biomass. One example is the gasification of black liquor, since this feedstock presents positive aspects related to its composition.

Nevertheless, when operating the SCWG, safety and operational issues should be planned and considered carefully. The plugging phenomena is not to be underestimated since this will cause enormous stress within the reactor which could lead to damages. In addition, the phenomenon of salt deposition suggests additional investigations on salt recovery and recycling.

\section{Acknowledgements}

Åbo Akademi Research Services are acknowledged for the funds provided.

\section{References}

[1] C. De Blasio, Fundamentals of Biofuels Engineering and Technology, Springer International Publishing, 2019. https://www.springer.com/us/book/9783030115982 (accessed April 1, 2019).

[2] C. De Blasio, Light Harvesting and Biomass Generation, in: Fundamentals of Biofuels Engineering and Technology, 1st ed., Springer International Publishing, 2019: pp. 13-30.

[3] W. Gądek, M. Mlonka-Mędrala, M. Prestipino, P. Evangelopoulos, S. Kalisz, W. Yang, Gasification and pyrolysis of different biomasses in lab scale system: A comparative study, E3S Web Conf. 10 (2016) 00024. doi:10.1051/e3sconf/20161000024.

[4] N. Cerone, F. Zimbardi, L. Contuzzi, M. Prestipino, M.O. Carnevale, V. Valerio, Air-steam and oxy-steam gasification of hydrolytic residues from biorefinery, Fuel Processing Technology. 167 (2017) 451-461. doi:10.1016/j.fuproc.2017.07.027.

[5] J.F. Pérez, A. Melgar, P.N. Benjumea, Effect of operating and design parameters on the gasification/combustion process of waste biomass in fixed bed downdraft reactors: An experimental study, Fuel. 96 (2012) 487-496. doi:10.1016/j.fuel.2012.01.064.

[6] A. Galvagno, M. Prestipino, S. Maisano, F. Urbani, V. Chiodo, Integration into a citrus juice factory of air-steam gasification and CHP system: Energy sustainability assessment, Energy Conversion and Management. 193 (2019) 7485. doi:10.1016/j.enconman.2019.04.067.

[7] A. Galvagno, M. Prestipino, V. Chiodo, S. Maisano, S. Brusca, R. Lanzafame, Energy Performance of CHP System Integrated with Citrus Peel Air-Steam Gasification: a Comparative Study, Energy Procedia. 126 (2017) 485-492. doi:10.1016/j.egypro.2017.08.233.

[8] S. Brusca, A. Galvagno, R. Lanzafame, A.M.C. Garrano, M. Messina, Performance Analysis of Biofuel Fed Gas Turbine, Energy Procedia. 81 (2015) 493-504. doi:10.1016/j.egypro.2015.12.123. 
[9] C. De Blasio, Notions of Biomass Gasification, in: Fundamentals of Biofuels Engineering and Technology, 1st ed., Springer International Publishing, Switzerland, 2019: pp. 307-334.

[10] M.J.J. Antal, Y. Matsumura, X. Xu, Catalytic gasification of wet biomass in supercritical water, Preprints of Papers, American Chemical Society, Division of Fuel Chemistry. 40 (1995). https://www.osti.gov/biblio/420484 (accessed May 1, 2019).

[11] C. De Blasio, G. Lucca, K. Özdenkci, M. Mulas, K. Lundqvist, J. Koskinen, M. Santarelli, T. Westerlund, M. Järvinen, A study on supercritical water gasification of black liquor conducted in stainless steel and nickel-chromiummolybdenum reactors, Journal of Chemical Technology \& Biotechnology. 91 (n.d.) 2664-2678. doi:10.1002/jctb.4871.

[12] M. Magdeldin, T. Kohl, C. De Blasio, M. Järvinen, S. Won Park, R. Giudici, The BioSCWG Project: Understanding the Trade-Offs in the Process and Thermal Design of Hydrogen and Synthetic Natural Gas Production, Energies. 9 (2016) 838. doi:10.3390/en9100838.

[13] C. De Blasio, M. Järvinen, Supercritical Water Gasification of Biomass, in: Encyclopedia of Sustainable Technologies. Abraham M Editor., First Edition, 2017: pp. 171-195.

[14] A. Kruse, Supercritical water gasification, Biofuels, Bioproducts and Biorefining. 2 (2008) $415-437$. doi:10.1002/bbb.93.

[15] C. De Blasio, S. De Gisi, A. Molino, M. Simonetti, M. Santarelli, M. Björklund-Sänkiaho, Concerning operational aspects in supercritical water gasification of kraft black liquor, Renewable Energy. 130 (2019) 891-901. doi:10.1016/j.renene.2018.07.004.

[16] I. Rönnlund, L. Myréen, K. Lundqvist, J. Ahlbeck, T. Westerlund, Waste to energy by industrially integrated supercritical water gasification - Effects of alkali salts in residual by-products from the pulp and paper industry, Energy. 36 (2011) 2151-2163. doi:10.1016/j.energy.2010.03.027.

[17] Wahyudiono, M. Sasaki, M. Goto, Recovery of phenolic compounds through the decomposition of lignin in near and supercritical water, Chemical Engineering and Processing: Process Intensification. 47 (2008) 1609-1619. doi:10.1016/j.cep.2007.09.001. 